\title{
Confirmation of QTL mapping and marker validation for partial seedling resistance to crown rot in wheat line ' $2-49$ '
}

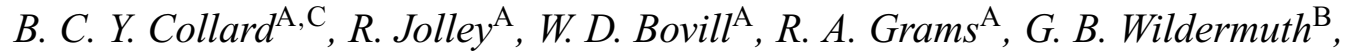 \\ and M.W. Sutherland ${ }^{\mathrm{A}, \mathrm{D}}$ \\ ${ }^{A}$ Centre for Systems Biology (formerly, Centre for Rural and Environmental Biotechnology), Faculty of Sciences, \\ University of Southern Queensland, Toowoomba, Qld 4350, Australia. \\ ${ }^{B}$ Leslie Research Centre, Queensland Department of Primary Industries and Fisheries, Toowoomba, Qld 4350, Australia. \\ ${ }^{\mathrm{C}}$ Present address: Hermitage Research Station, Queensland Department of Primary Industries and Fisheries, \\ Warwick, Qld 4370, Australia. \\ DCorresponding author. Email: marksuth@usq.edu.au
}

\begin{abstract}
We have tested the efficacy of putative microsatellite single sequence repeat (SSR) markers, previously identified in a 2-49 (Gluyas Early/Gala) $\times$ Janz doubled haploid wheat (Triticum aestivum) population, as being linked to partial seedling resistance to crown rot disease caused by Fusarium pseudograminearum. The quantitative trait loci (QTLs) delineated by these markers have been tested for linkage to resistance in an independent Gluyas Early $\times$ Janz doubled haploid population. The presence of a major QTL on chromosome 1DL (QCr.usq-1D1) and a minor QTL on chromosome 2BS (QCr.usq-2B1) was confirmed. However, a putative minor QTL on chromosome 2A was not confirmed. The QTL on 1D was inherited from Gluyas Early, a direct parent of 2-49, whereas the 2B QTL was inherited from Janz. Three other putative QTLs identified in 2-49 $\times$ Janz (on 1AL, 4BL, and 7BS) were inherited by 2-49 from Gala and were not able to be confirmed in this study. The screening of SSR markers on a small sample of elite wheat genotypes indicated that not all of the most tightly linked SSR markers flanking the major QTLs on 1D and 1A were polymorphic in all backgrounds, indicating the need for additional flanking markers when backcrossing into some elite pedigrees. Comparison of SSR haplotypes with those of other genotypes exhibiting partial crown rot resistance suggests that additional, novel sources of crown rot resistance are available.
\end{abstract}

Additional keywords: targetted mapping, QTL resolution, 1-LOD support interval, allelic homoplasy.

\section{Introduction}

Resistance to the fungal disease crown rot, caused by Fusarium pseudograminearum, is a high priority for wheat breeding in Australia (Burgess et al. 2001). Breeding for crown rot resistance is difficult due to time-consuming, technically laborious and expensive methods for phenotypic screening (Wildermuth and McNamara 1994; Wildermuth et al.2001) in which disease expression is strongly influenced by environmental factors (Beddis and Burgess 1992). Selection for this trait would be greatly assisted by the development of closely linked molecular markers suitable for deployment in a marker assisted selection (MAS) program. To date, there have been only 3 published reports of the identification of markers associated with crown rot resistance (Wallwork et al. 2004; Collard et al. 2005; Bovill et al. 2006).

'QTL confirmation' and 'marker validation' are critical stages prior to the deployment of molecular markers for MAS (Langridge et al. 2001; Sharp et al. 2001; Zhou et al. 2003).
Quantitative trait loci (QTL) confirmation refers to the process of confirming the accuracy of QTL mapping results based on initial experiments. 'Marker validation' refers to the process of confirming the effectiveness of markers associated with putative QTLs in one population for indicating the target phenotype in independent populations and other germplasm, which incorporate those QTLs. So far, none of the QTLs associated with crown resistance has been confirmed in independent populations, nor have markers been validated in a range of genotypes.

In a previous study, we reported the identification of microsatellite single sequence repeat (SSR) markers associated with 2 major QTLs on chromosomes 1D and $1 \mathrm{~A}$, and 4 minor QTLs on $2 \mathrm{~A}, 2 \mathrm{~B}, 4 \mathrm{~B}$, and $7 \mathrm{~B}$ for crown rot resistance in a $2-49 \times$ Janz doubled haploid population (Collard et al. 2005). 2-49 is an important breeding line that possesses both seedling and adult plant (field) resistance (Wildermuth and McNamara 1994). The objectives of this study were to $(i)$ confirm the QTLs detected in the 
$2-49 \times$ Janz population in an independent mapping population; (ii) test the level of polymorphism of tightlylinked markers in different genetic backgrounds into which these resistance QTLs might be backcrossed; and (iii) compare the SSR haplotype of 2-49 at these loci with other crown rot resistant genotypes.

\section{Materials and methods}

\section{Mapping population and plant material}

The original $2-49 \times$ Janz doubled haploid mapping population of 153 doubled haploid (DH) lines is described in Collard et al. (2005). 2-49 is a line showing partial resistance to crown rot, which resulted from a Gluyas Early $\times$ Gala cross in which both parents are partially resistant (Wildermuth and McNamara 1994). In total, $90 \mathrm{DH}$ lines derived from Gluyas Early $\times$ Janz were used to confirm the QTL mapping results from Collard et al. (2005).

A selection of 16 genotypes, which either expressed partial crown rot resistance or represented pedigrees that are important in Australia's northern wheatbelt, was made in order to test the effectiveness of previously identified SSR markers in discriminating between crown rot resistant and susceptible genotypes. Sumai-3, a widely used breeding line with resistance to Fusarium head blight (Liu and Anderson 2003), was included due to observations that this genotype also displays field resistance to crown rot (G. Wildermuth, unpublished data) Seed was obtained from the Leslie Research Centre, Toowoomba, Australia. DNA was extracted from leaf material of 14-day-old seedlings, using Qiagen DNA extraction kits.

\section{Phenotypic evaluation}

Seedlings were phenotyped at 3 weeks of age using the glasshouse method described by Wildermuth and McNamara (1994). The Gluyas Early $\times$ Janz population was phenotyped in 3 separate glasshouse experiments using the glasshouse facility at the Leslie Research Centre, Toowoomba. Experiment 1 was conducted from 9 to 30 July 2003, Expt 2 was conducted from 29 April to 20 May 2004, and Expt 3 was conducted from 29 June to 20 July 2004 . Seedling leaf sheath infection was rated in duplicated pots using a 5-class scale where: 0 , no infection; $1,0-25 \%$; $2,25-50 \% ; 3,50-75 \%$; and $4,75-100 \%$ visible symptoms. Three leaf sheaths were rated for each individual plant to produce a disease score out of 12. Disease scores were then expressed as percentage infection based on the highly susceptible cultivar Puseas.

\section{DNA extraction and molecular marker analysis}

DNA extractions, polymerase chain reaction (PCR), and visualisation of PCR products have been described in Collard et al. (2005). Twenty-five SSR markers in the chromosomal regions containing QTLs detected in the 2-49 $\times$ Janz mapping population (Collard et al. 2005) were used to screen 2-49, Gluyas Early, Gala, and Janz in order to infer the origin of resistance QTLs in 2-49. Additional markers that were tightly linked to the QTLs based on consensus maps were also screened across the parental lines. Polymorphic markers were then used to genotype the Gluyas Early $\times$ Janz population. Genotyping of markers located on chromosome 1D was performed in duplicate and independently scored, in order to minimise genotyping errors. Linkage maps were constructed using Map Manager QTX Version b20 (Manly et al. 2001). SSR markers were assigned to chromosomes based on previously published maps (Roder et al. 1998; Pestsova et al. 2000; Harker et al. 2001; Gupta et al. 2002) and consensus maps (Appels 2003; Somers et al. 2004). In total, 10 SSR markers that were tightly linked to the QTLs on chromosomes 1D and 1A were used to genotype the 16 wheat lines in Table 5.

\section{Statistical and QTL analysis}

One-way ANOVA was performed on disease scores for the separate glasshouse experiments for the Gluyas Early $\times$ Janz population to determine differences between trials and genetic variation (SPSS version 11, SPSS Inc. Chicago, IL, USA). The least significant difference (1.s.d.) test was conducted in order to compare population means of individual glasshouse experiments and individual DH lines of the Gluyas Early $\times$ Janz population within each experiment. Simple interval mapping (SIM) and composite interval mapping (CIM) were performed using MapManager QTX (Manly et al. 2001). Likelihood ratio statistic (LRS) values were converted into logarithm of odds (LOD) values by dividing by 4.6 (Manly et al. 2001). CIM was performed by including background unlinked markers exceeding the significance threshold. Significance levels were determined with 1000 permutation tests, and QTLs were classified as 'highly significant', 'significant', and 'suggestive', based on the guidelines reported by Lander and Kruglyak (1995) and implemented by Map Manager QTX (Manly et al.2001). For significant or highly significant QTLs, 95\% confidence intervals for QTL position were calculated using the 1-LOD support interval. Chromosome maps were made using MapChart Version 2.1 (Voorrips 2002).

\section{Results}

\section{Phenotypic distributions}

The histograms of disease scores for all phenotypic trials indicated continuous distributions (Fig. 1). The mean disease scores for parental lines and doubled haploid lines are indicated in Table 1 . There was a highly significant difference between population means of the 3 separate glasshouse trials for Gluyas Early $\times \operatorname{Janz}(P<0.001)$ (Table 1). In each trial there was evidence of transgressive segregation in which some lines either significantly exceeded or fell below the disease scores of the 2 parents.

\section{Genotyping of an independent population}

Although not all of the markers used for QTL mapping in the $2-49 \times$ Janz population were polymorphic in Gluyas Early $\times$ Janz, partial maps were constructed for those chromosomal regions that contained QTLs for crown rot resistance in the 2-49 $\times$ Janz population. In total, $40 \mathrm{SSR}$ markers were mapped in the Gluyas Early $\times$ Janz population (Table 2). Some primers generated marker alleles or additional marker alleles that were unlinked to the target chromosomes. Generally, the order of markers between populations was conserved, although there were some instances in which the marker order and distances between markers varied between the two populations (Fig. 2).

Screening Gluyas Early and Gala with markers linked to the QTLs detected in 2-49 enabled the origin of these loci to be deduced (Table 3).

\section{QTL analysis}

The detection of QTLs on chromosome 1D in the Gluyas Early $\times$ Janz mapping population is reported in Table 4 . Significant QTLs were detected on chromosome 1D in 2 out of the 3 glasshouse experiments; a QTL on 

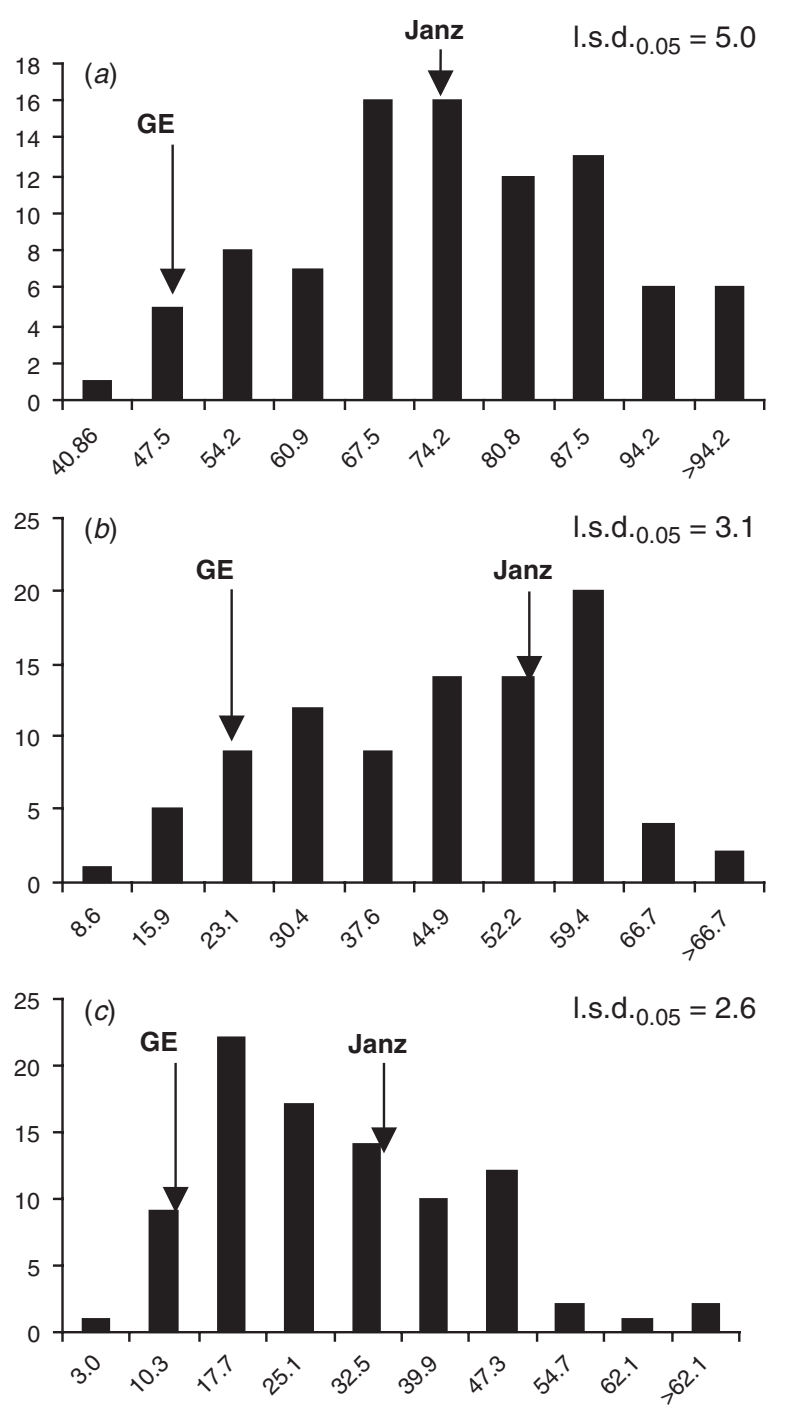

Fig. 1. Frequency distributions of mean disease scores (expressed as $\%$ disease relative to the susceptible cultivar Puseas) of the Gluyas Early $(\mathrm{GE}) \times$ Janz DH population. The histograms are shown for the individual glasshouse: (a) Expt 1; (b) Expt 2; and (c) Expt 3. Least significant difference at $P=0.05$ (1.s.d.) values are indicated.

Table 1. Mean disease scores (expressed as percentage of disease relative to the susceptible cultivar Puseas) for parents and doubled haploid lines for the 3 independent experiments using the Gluyas Early $x$ Janz population

Mean DH population scores followed by the same letters are not significantly different at $P=0.05$ (1.s.d.) multiple comparison test

\begin{tabular}{lcccc}
\hline Expt & Gluyas Early & Janz & DH population & s.d. \\
\hline 1 & 50.7 & 76.0 & $70.9 \mathrm{a}$ & 15.5 \\
2 & 24.3 & 53.3 & $40.4 \mathrm{~b}$ & 14.3 \\
3 & 12.4 & 38.4 & $25.7 \mathrm{c}$ & 23.9 \\
\hline
\end{tabular}

chromosome 1D that was just below the significance threshold was detected for Expt 2. LOD plots of interval mapping analysis and 1-LOD support (95\% confidence)
Table 2. Numbers and location of mapped markers in Gluyas Early $x$ Janz

\begin{tabular}{lccccccc}
\hline Population & \multicolumn{7}{c}{ Chromosomes } \\
& 1A & $1 \mathrm{D}$ & $2 \mathrm{~A}$ & $2 \mathrm{~B}$ & $4 \mathrm{~B}$ & 7B & $\mathrm{U}^{\mathrm{A}}$ \\
\hline Gluyas Early $\times$ Janz & 4 & 8 & 4 & 4 & 2 & 2 & 16 \\
\hline
\end{tabular}

${ }^{\mathrm{A}} \mathrm{U}$, Unlinked to target chromosomes.

intervals for QTLs are presented in Fig. 2. Additional QTLs located on other chromosomes were detected in the first and third experiments - suggestive QTLs were detected on chromosomes $2 \mathrm{~A}$ and $2 \mathrm{~B}$ in the first experiment, and only 2B in Expt 3. The QTL on chromosome 2A was detected using simple interval mapping but not composite interval mapping. The QTL on chromosome 2B was detected using both QTL analysis methods. QTLs were detected on 1D (significant) and 2B (suggestive) using mean disease score values from all 3 experiments (Table 4 ). There were no QTLs detected on chromosomes $1 \mathrm{~A}, 4 \mathrm{~B}$, and $7 \mathrm{~B}$, which is consistent with the inheritance of these chromosomal regions from Gala.

\section{Evaluation of important SSR markers in selected genotypes}

The 5 most tightly linked SSR markers within the vicinity of the QTLs on chromosomes 1D and 1A in the $2-49 \times$ Janz population were selected to determine marker allele sizes in these regions for a range of other genotypes (Table 5). These genotypes included a range of sources for both seedling and field-based partial resistances and important pedigree lines in the Northern region. The SSR genotyping results indicated that only a few markers could be used for MAS in crosses derived from these genotypes. For chromosome 1D, Xcfd19 and Xgwm337 are unique to Gluyas Early and its progeny 2-49, when compared with all lines screened. In crosses derived from most other genotypes except Hartog and some of its derivatives (e.g. QT8766, Sunbrook, and Sunstate), Xwmc429 and/or Xwmc216 are also available as closely linked markers for resistance. Similarly, the Gala and 2-49 haplotypes for the QTL on chromosome 1A provide 2-5 SSRs polymorphic in the range of genotypes screened. In particular at least two out of the 3 SSRs Xwmc24, Xwmc312, and Xbarc148 are polymorphic in all other lines compared with 2-49 or Gala. When compared with 2-49 and its parents, all other identified sources of seedling or field resistance in Table 5 show different haplotypes.

\section{Discussion}

\section{QTL analysis of Gluyas Early $\times$ Janz}

The distribution of marker allele sizes in 2-49, Gluyas Early, and Gala together with QTL analysis in the Gluyas Early $\times$ Janz population indicates that the major QTL 
2-49 $\times$ Janz

Gluyas Early × Janz

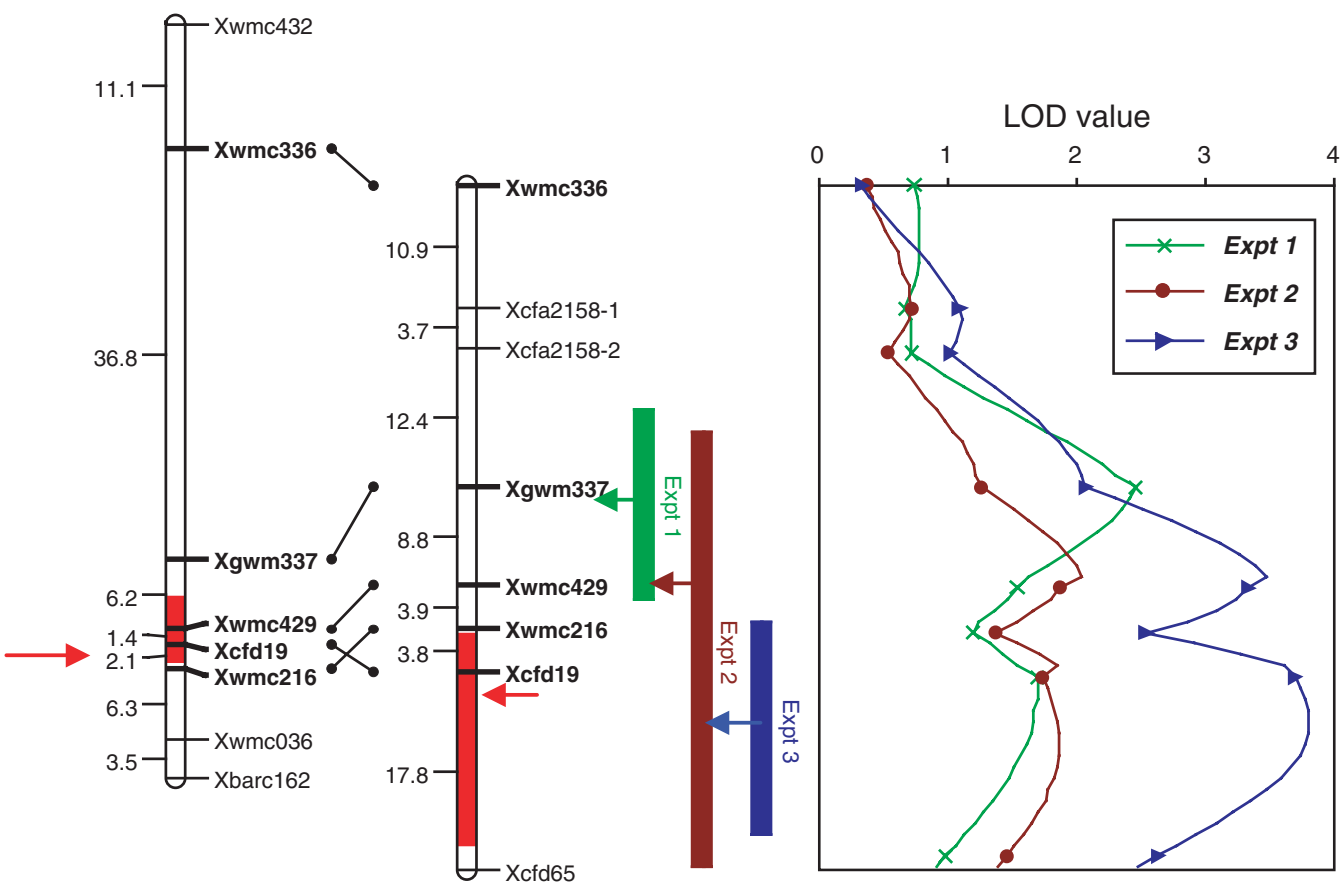

Fig. 2. Comparison of QTL position for seedling resistance on chromosome $1 \mathrm{D}$ between $2-49 \times$ Janz and Gluyas Early $\times$ Janz mapping populations. Common markers are indicated in bold. The 1-LOD support interval for QTL positions is indicated by the filled regions within the chromosomes. Vertical bars indicate the 1-LOD support intervals for the Gluyas Early $\times$ Janz population for the 3 experiments individually. The arrows indicate the most likely position of the QTL based on interval mapping results.

detected on chromosome 1D in the 2-49 $\times$ Janz population was inherited from Gluyas Early. This QTL consistently explains a relatively large proportion of the phenotypic variance for crown rot resistance and would be an ideal candidate for MAS. The QTL detected on 2B was inherited from Janz, which is consistent with the contribution of a minor resistance QTL from Janz in the $2-49 \times$ Janz population and the detection of transgressive segregants (Fig. 1; Collard et al. 2005). No QTLs were detected on chromosomes $1 \mathrm{~A}, 4 \mathrm{~B}$, or $7 \mathrm{~B}$ in the Gluyas Early $\times$ Janz population, which is consistent with these regions in 2-49 being inherited from Gala (Table 3). Attempts to confirm these QTLs in other populations are continuing.

Suggestive QTLs, such as those detected in Gluyas Early $\times$ Janz on 2A and 2B, may indicate false positive QTLs (Lander and Kruglyak 1995). However, since the QTL on 2B has now been detected in both 2-49 $\times$ Janz and Gluyas Early $\times$ Janz populations, it is likely that this is a genuine QTL for crown rot resistance with small effects. In contrast, the suggestive QTL on 2A is probably not genuine because it was only detected in a single experiment (with a very low LOD score) and was not detected using CIM, which is considered to be more accurate compared with SIM. This result was also observed in our study of the $2-49 \times$ Janz population
(Collard et al. 2005). Compared with CIM, SIM analysis may be greatly affected by unlinked QTLs and small population sizes, which increase the chance of producing Type I errors (i.e. identifying a QTL when no QTLs exist) (Jansen 1994, 2001).

One important difference in QTL analysis between the 2-49 $\times$ Janz and Gluyas Early $\times$ Janz populations was the position of QTLs. The most likely position of the QTL on chromosome 1D (in the 2-49 $\times$ Janz population) was located between the SSR markers Xcfd19 and Xwmc216, whereas in the Gluyas Early $\times$ Janz population, the most likely position of the QTL was between Xwmc429 and Xgwm337 or between Xcfd19 and Xcfd65 (Fig. 2). Furthermore, the 1-LOD support intervals were large and there were only small regions of overlap between the 3 glasshouse experiments. This lack of precision was probably attributable to the differences in marker order and map distances between populations, and the low power of QTL detection (i.e. large confidence intervals) when small populations are used for QTL mapping (Beavis 1998; Kearsey and Farquhar 1998; Melchinger et al. 1998). This is in agreement with simulation studies in QTL mapping, which have indicated that the confidence intervals may still be very wide even for QTLs with large effects (Hyne et al. 1995). This has important 
Table 3. Inheritance of 2-49 SSR alleles from Gluyas Early and Gala parents

The 2-49 alleles are indicated in bold and underlined. Janz was also tested in order to identify polymorphic markers for mapping. NP, not polymorphic; SSR marker allele size estimated in base pairs

\begin{tabular}{|c|c|c|c|c|c|}
\hline Marker & Source & $2-49$ & Gluyas Early & Gala & Janz \\
\hline & & Chr. 1A & & & \\
\hline Xwmc24 & Gala & 130 & 138 & $\underline{130}$ & 138 \\
\hline Xbarc148 & NP & $\overline{190}$ & $\underline{190}$ & $\overline{190}$ & 185 \\
\hline Xgwm164 & Gala & 120 & 130 & 120 & 125 \\
\hline Xwmc120 & Gala & $\overline{150}$ & 155 & $\overline{\mathbf{1 5 0}}$ & 155 \\
\hline \multirow[t]{2}{*}{ Xwmc312 } & $\mathrm{NP}$ & $\underline{\underline{212}}$ & $\underline{212}$ & $\overline{\underline{212}}$ & 230 \\
\hline & & Chr. 1D & & & \\
\hline Xgwm337 & Gluyas Early & 190 & 190 & 195 & 170 \\
\hline Xwmc429 & $\mathrm{NP}$ & $\overline{220}$ & $\overline{220}$ & 220 & 200 \\
\hline Xcfd19 & Gluyas Early & $\overline{280}$ & $\overline{280}$ & $\overline{278}$ & 260 \\
\hline Xwmc216 & Gluyas Early & 125 & 125 & 120 & 120 \\
\hline \multirow[t]{2}{*}{ Xwmc036 } & $\mathrm{NP}$ & $\underline{112}$ & $\underline{112}$ & $\underline{112}$ & 114 \\
\hline & & Chr. $2 A$ & & & \\
\hline Xgwm515 & Gluyas Early & 170 & 170 & 165 & 165 \\
\hline Xgwm339 & Gluyas Early & $\overline{170}$ & $\overline{170}$ & 155 & 160 \\
\hline Xcfa2263 & $\mathrm{NP}$ & $\overline{150}$ & $\overline{150}$ & $\underline{150}$ & 145 \\
\hline \multirow[t]{2}{*}{ Xgwm558 } & Gluyas Early & $\overline{100}$ & $\overline{100}$ & $\overline{115}$ & 108 \\
\hline & & Chr. $2 B$ & & & \\
\hline Xgwm388 & Gala & $\underline{170}$ & 162 & $\underline{170}$ & 165 \\
\hline Xbarc349-1 & Gluyas Early & $\overline{92}$ & 92 & $\overline{108}$ & 94 \\
\hline Xcfa2278 & $\mathrm{NP}$ & $\underline{130}$ & $\underline{130}$ & 130 & 120 \\
\hline Xgwm271 & $\mathrm{NP}$ & $\underline{148}$ & $\underline{148}$ & $\underline{148}$ & 150 \\
\hline \multirow[t]{2}{*}{ Xwmc441 } & Gala & $\underline{175}$ & $\overline{160}$ & $\overline{175}$ & 160 \\
\hline & & Chr. $4 B$ & & & \\
\hline Xgwm192-2 & Gala & $\underline{180}$ & 190 & $\underline{180}$ & 185 \\
\hline Xgwm165 & Gala & $\overline{240}$ & 247 & $\overline{240}$ & 245 \\
\hline \multirow[t]{2}{*}{ Xgwm251 } & Gala & $\underline{\overline{100}}$ & 90 & $\overline{100}$ & 110 \\
\hline & & Chr. $7 B$ & & & \\
\hline Xgwm46 & Gala & $\underline{158}$ & 166 & $\underline{158}$ & 146 \\
\hline Xgwm400 & Gala & $\underline{\overline{130}}$ & 146 & $\overline{130}$ & 146 \\
\hline Xgwm537 & Gala & $\overline{220}$ & 226 & $\overline{220}$ & 238 \\
\hline
\end{tabular}

implications for MAS, since the efficiency of markers greatly depends on the precision of the QTL mapping study. The use of larger population sizes would be necessary to more accurately determine marker order and distances, and to further resolve the position of QTLs.

\section{Utility of $1 D$ and $1 A$ crown rot markers in MAS}

Although only a small number of genotypes was screened with SSR markers associated with QTLs on chromosomes 1D and $1 \mathrm{~A}$, only 2 markers (Xcfd19 and Xgwm337) possessed alleles that were uniquely linked to the major QTL on 1D from 2-49 and did not occur in the other genotypes screened. Therefore these markers should be useful for screening for the presence of the QTL on 1D in 2-49-derived populations, although additional susceptible genotypes should be tested for further confirmation. The detection of identical marker alleles in resistant and susceptible genotypes for some markers that were tightly linked to the QTL on 1D (e.g. Xwmc216 or Xwmc429) prevents the use of these markers for backcrossing the 1D resistance into Hartog and its derivatives, which possess important agronomic traits. This has been referred to as 'allelic homoplasy' (Grimaldi and Crouau-Roy 1997; Hayden et al. 2004). In the case of the QTL on 1A, the screening of 3 SSRs will provide at least 2 polymorphic markers in crosses of Gala or 2-49 to the other lines in Table 5. The failure to detect SSR marker alleles that are diagnostic in all crosses has been reported for other disease resistance traits in wheat. For example, a 120 base pair marker (generated by the SSR primer gwm533) was diagnostic for the $S r 2$ gene for stem rust for all but 4 susceptible Australian cultivars (Spielmeyer et al. 2003). This attribute of the SSR markers highlights the necessity to test markers against the full range of pedigree sources prior to use in MAS even when a tightly linked pair of flanking markers $(2.1 \mathrm{cM})$ has been identified in the original mapping study. Although single, tightly linked markers can still be effective for MAS in the absence of 'perfect' markers within a gene (Wilcox et al. 2002; Zhou et al. 2003), the identification of a 'window' or 'suite' of flanking markers is preferable for each QTL, since different pairs of flanking markers can be used in different backgrounds (Langridge et al. 2001; Sharp et al. 2001). However, in practice this level of marker density

Table 4. Detection of QTLs for crown rot resistance

Significant and highly significant LOD values are shown in bold. Classification of QTLs: highly significant (HS), significant (S), suggestive (Sg), not significant (n.s.)

\begin{tabular}{|c|c|c|c|c|c|c|c|}
\hline Chr. & $2-49 \times \operatorname{Janz}^{\mathrm{A}}$ & $\begin{array}{l}\text { Source of } \\
\text { resistance } \\
\text { allele }\end{array}$ & Expt 1 & Expt 2 & $\begin{array}{l}\text { Gluyas Early } \times \\
\text { Expt } 3\end{array}$ & $\begin{array}{l}\text { Mean } \\
\text { (all } 3 \text { Expts) }\end{array}$ & $\begin{array}{l}\text { Source of resistance } \\
\text { alleles in } 2-49 \times \text { Janz }\end{array}$ \\
\hline $1 \mathrm{~A}$ & S, $4.0(9 \%)$ & $2-49$ & n.s. & n.s. & n.s. & n.s. & Gala \\
\hline 1D & HS, $8.5(21 \%)$ & $2-49$ & S, $2.5(12 \%)$ & $\mathrm{Sg}, 2.0(10 \%)$ & HS, $3.8(20 \%)$ & S, $3.5(19 \%)$ & Gluyas Early \\
\hline $2 \mathrm{~A}$ & $\mathrm{Sg}^{\mathrm{B}}, 1.0(6 \%)$ & $2-49$ & $\mathrm{Sg}^{\mathrm{B}}, 1.2(6 \%)$ & n.s. & n.s. & n.s. & Gluyas Early \\
\hline $2 \mathrm{~B}$ & $\mathrm{Sg}, 1.9(4 \%)$ & Janz & $\mathrm{Sg}, 1.7(10 \%)$ & n.s. & $\mathrm{Sg}, 1.2(6 \%)$ & $\mathrm{Sg}, 1.0(5 \%)$ & Janz \\
\hline $4 \mathrm{~B}$ & $\mathrm{Sg}, 1.9(4 \%)$ & $2-49$ & n.s. & n.s. & n.s. & n.s. & Gala \\
\hline $7 \mathrm{~B}$ & $\mathrm{Sg}, 2.5(6 \%)$ & $2-49$ & n.s. & n.s. & n.s. & n.s. & Gala \\
\hline
\end{tabular}

${ }^{\mathrm{A}}$ Data from Collard et al. (2005).

${ }^{\mathrm{B}}$ QTL detected using simple interval mapping but not composite interval mapping. 
Table 5. Estimated allele sizes (base pairs) for chromosome 1D and 1A SSR markers for different genotypes Genotypes with 2-49 markers alleles are indicated in bold and underlined, in shaded boxes

\begin{tabular}{|c|c|c|c|c|c|c|c|c|c|c|c|}
\hline \multirow[t]{2}{*}{ Genotype } & \multirow[t]{2}{*}{ Classification $^{\mathrm{A}}$} & \multicolumn{5}{|c|}{ Chromosome 1D } & \multicolumn{5}{|c|}{ Chromosome 1A } \\
\hline & & Xcfd19 & Xwmc216 & Xwmc429 & Xgwm337 & Xwmc36 & Xwmc120 & Xwmc24 & Xwmc312 & Xbarc148 & Xgwm164 \\
\hline $2-49$ & PR (seedling) & $\underline{290}$ & $\underline{128}$ & $\underline{220}$ & $\underline{188}$ & $\underline{112}$ & $\underline{150,154}$ & $\underline{132}$ & $\underline{212}$ & $\underline{198}$ & $\underline{112}$ \\
\hline Gluyas Early & PR (seedling) & $\underline{290}$ & $\underline{128}$ & $\underline{220}$ & $\underline{188}$ & $\underline{112}$ & 158 & $\overline{136}$ & $\underline{212}$ & $\underline{198}$ & $\overline{124}$ \\
\hline Gala & PR (seedling) & $\overline{285}$ & $\overline{122}$ & $\overline{218}$ & $\overline{190}$ & $\underline{112}$ & $\underline{150,154}$ & 132 & $\underline{212}$ & $\underline{198}$ & $\underline{112}$ \\
\hline CPI133814 & PR (seedling) & 270 & 116 & 190 & 150 & 114 & 160 & $\overline{115}$ & 210 & $\overline{196}$ & 118 \\
\hline IRN497 & PR (seedling) & 268 & 122 & 218 & 172 & 114 & 150,154 & $\underline{132}$ & 222 & 196 & $\underline{112}$ \\
\hline W21MMT70 & PR (seedling) & 268 & 122 & $\underline{220}$ & 168 & $\underline{112}$ & $\overline{150,154}$ & $\overline{131}$ & 222 & 193 & $\overline{114}$ \\
\hline Kukri & PR (field) & 270 & 128 & 210 & 164 & $\underline{112}$ & 158 & 148 & 222 & 194 & 118 \\
\hline Lang & PR (field) & 270 & $\overline{122}$ & 205 & 160 & $\overline{114}$ & 158 & 136 & 230 & 196 & $\underline{112}$ \\
\hline Mendos & PR (field) & Null & $\underline{128}$ & 215 & 172 & $\underline{112}$ & 158 & 131 & 228 & $\underline{198}$ & $\overline{124}$ \\
\hline Sunco & PR (field) & 268 & $\overline{122}$ & 210 & 164 & $\overline{114}$ & 150,154 & 136 & $\underline{212}$ & $\overline{196}$ & 114 \\
\hline Sumai3 & PR (field) & 268 & 122 & 210 & 164 & 114 & 158 & 136 & 200 & 196 & $\underline{112}$ \\
\hline Batavia & Susceptible & 275 & 122 & $\underline{220}$ & 172 & $\underline{112}$ & 150,154 & 140 & 220 & 195 & $\overline{118}$ \\
\hline CPI133872 & Susceptible & 285 & 118 & 195 & 170 & $\underline{112}$ & 158 & 120 & 210 & 192 & 124 \\
\hline Hartog & Susceptible & Null & $\underline{128}$ & $\underline{220}$ & 174 & $\underline{112}$ & 158 & 134 & 220 & 195 & 118 \\
\hline Janz & Susceptible & 265 & 122 & 210 & 164 & 114 & 158 & 136 & 230 & 196 & 114 \\
\hline Puseas & Susceptible & 275 & 122 & 215 & 172 & 112 & Null & 120 & 226 & 196 & 120 \\
\hline QT8766 & Susceptible & 270 & $\underline{128}$ & $\underline{220}$ & 175 & $\overline{114}$ & 158 & 137 & 228 & 196 & 114 \\
\hline Sunbrook & Susceptible & 275 & $\underline{128}$ & $\underline{220}$ & 172 & 114 & $\underline{150,154}$ & 138 & $\underline{212}$ & 195 & 114 \\
\hline Sunstate & Susceptible & 275 & $\underline{128}$ & $\underline{220}$ & 172 & $\underline{112}$ & $\overline{150,154}$ & $\underline{132}$ & 220 & 195 & 118 \\
\hline Vasco & Susceptible & 275 & 122 & 210 & 164 & $\overline{114}$ & 158 & $\overline{136}$ & $\underline{212}$ & 196 & 114 \\
\hline
\end{tabular}

${ }^{A}$ PR, partial resistance; Classifications derived from Liu et al. (2004), Wallwork et al. (2004), Wildermuth and McNamara (1994), and Wildermuth et al. (2001).

is not always available due to low polymorphism levels or to a lack of identified markers in critical regions. In this study we screened all publicly available SSR markers previously mapped to these regions. In critical regions lacking suitable polymorphic SSR markers, other types of markers such as single nucleotide polymorphisms (SNPs) (Spielmeyer et al. 2003) and sequence-tagged microsatellites (STMs) (Hayden et al. 2004) may be necessary to discriminate between different genotypes.

\section{Marker-assisted evaluation of additional crown rot resistant genotypes}

The screening of important SSR markers associated with disease resistance QTLs can provide a useful representation of the relationship of a single genotype to other germplasm accessions (Liu and Anderson 2003; McCartney et al. 2004). Although some 2-49 SSR marker alleles were identical to marker alleles from different genotypes with crown rot resistance, the 2-49 haplotype, derived from a total of $10 \mathrm{SSR}$ loci on 1D and 1A, appears to be unique among other genotypes with partial seedling resistance and field resistance to crown rot. This implies that distinct partially resistant genotypes such as W21MMT70 and IRN497 may represent novel sources of partial resistance that can be used to pyramid multiple resistance QTLs together. The recent detection of novel QTLs on 2D and 5D in a W21MMT70 $\times$ Mendos doubled haploid population supports this hypothesis (Bovill et al.2006). Further genetic analysis to test these possibilities is currently underway, based on QTL mapping using populations containing these sources, haplotyping of critical regions, and phenotypic screening of half-diallel populations.

\section{Concluding remarks}

We have confirmed 2 QTLs for crown rot resistance that were originally identified in a 2-49 $\times$ Janz population, including a major QTL on chromosome 1DL (from 2-49) and a minor QTL on chromosome 2BS (from Janz). We propose that these be designated for future reference as $Q C r . u s q-1 D 1$ and QCr.usq-2B1, respectively. A suite of SSR markers that are closely linked to QCr.usq-1D1 has been identified. These markers can be used for MAS for crown rot resistance in a range of backgrounds. Implementation of the use of these markers in selecting 2-49 backcross material is currently underway in several breeding programs. Confirmation of the 3 QTLs in 2-49 inherited from Gala (on 1AL, 4BL, and 7BS) is in progress.

\section{Acknowledgments}

We thank Matt Davis, Sally Coverdale, and Boyd McNamara (Leslie Research Centre, Toowoomba) for excellent technical assistance with the glasshouse experiments. We also thank the Grains Research and Development Corporation (GRDC) for providing funding for this research within the Australian Winter Cereals Molecular Marker Program.

\section{References}

Appels R (2003) A consensus molecular genetic map for wheat a cooperative international effort. In 'Proceedings of the 10th International Wheat Genetics Symposium'. Paestum, Italy. (Ed. NE Progna) (Instituto Sperimentale per la Cerealicoltura: Rome, Paestum, Italy)

Beavis W (1998) QTL analyses: power, precision and accuracy. In 'Molecular dissection of complex traits'. (Ed. AH Paterson) (CRC Press: Boca Raton, FL) 
Beddis AL, Burgess LW (1992) The influence of plant water stress on infection and colonization of wheat seedlings by Fusarium graminearum Group 1. Phytopathology 82, 78-83.

Bovill WD, Ma W, Ritter K, Collard BCY, Davis M, Wildermuth GB, Sutherland MW (2006) Identification of novel QTLs for resistance to crown rot in the doubled haploid wheat population 'W21MMT70' × 'Mendos'. Plant Breeding, (In press).

Burgess LW, Backhouse D, Summerell BA, Swan LJ (2001) Crown rot of wheat. In 'Fusarium'. (Eds BA Summerell, JF Leslie, D Backhouse, WL Bryden, LW Burgess) pp. 271-294. (APS Press: St Paul, MN)

Collard BCY, Grams RA, Bovill WD, Percy C, Jolley R, Lehmensiek A, Wildermuth G, Sutherland MW (2005) Development of molecular markers for crown rot resistance in wheat: mapping of QTLs for seedling resistance in a '2-49' $\times$ 'Janz' population. Plant Breeding 124, 532-537. doi: 10.1111/j.1439-0523.2005.01163.x

Grimaldi MC, Crouau-Roy B (1997) Microsatellite allelic homoplasy due to variable flanking sequences. Journal of Molecular Evolution 44, 336-340. doi: 10.1007/PL00006151

Gupta PK, Balyan HS, Edwards K, Isaac P, Korzun V, Rader M, Gautier M-F, Joudrier P, Schlatter A, Dubcovsky J, De la Pena R, Khairallah M, Penner G, Hayden M, Sharp P, Keller B, Wang R, Hardouin J, Jack P, Leroy P (2002) Genetic mapping of 66 new microsatellite (SSR) loci in bread wheat. Theoretical and Applied Genetics 105, 413-422. doi: 10.1007/s00122-002-0865-9

Harker N, Rampling LR, Shariflou MR, Hayden MJ, Holton TA, Morell MK, Sharp PJ, Henry RJ, Edwards KJ (2001) Microsatellites as markers for Australian wheat improvement. Australian Journal of Agricultural Research 52, 1121-1130. doi: 10.1071/AR01025

Hayden MJ, Kuchel H, Chalmers KJ (2004) Sequence tagged microsatellites for the Xgwm533 locus provide new diagnostic markers to select for the presence of stem rust resistance gene $\mathrm{Sr} 2$ in bread wheat (Triticum aestivum L.). Theoretical and Applied Genetics 109, 1641-1647. doi: 10.1007/s00122-004-1787-5

Hyne V, Kearsey MJ, Pike DJ, Snape JW (1995) QTL analysis: unreliability and bias in estimation procedures. Molecular Breeding 1, 273-282.

Jansen RC (1994) Controlling the Type 1 and Type 2 errors in mapping quantitative trait loci. Genetics 138, 871-881.

Jansen RC (2001) Quantitative trait loci in inbred lines. In 'Handbook of statistical genetics'. (Eds DJ Balding, M Bishop, C Cannings) pp. 567-597. (Wiley: New York)

Kearsey MJ, Farquhar GL (1998) QTL analysis in plants; where are we now? Heredity 80, 137-142. doi: 10.1046/j.13652540.1998.00500.x

Lander ES, Kruglyak L (1995) Genetic dissection of complex traits: guidelines for interpreting and reporting linkage results. Nature Genetics 11, 241-247. doi: 10.1038/ng1195-241

Langridge P, Lagudah E, Holton T, Appels R, Sharp P, Chalmers K (2001) Trends in genetic and genome analyses in wheat: a review. Australian Journal of Agricultural Research 52, 1043-1077. doi: 10.1071/AR01082

Liu C, Mitter V, Mager T, Ban T, Chakraborty S (2004) Relationships between resistance to Fusarium head blight and crown rot in hexaploid wheat. In '4th International Crop Science Congress'. 26 Sept.-1 Oct. 2004, Brisbane, Australia. (The Regional Institute Limited: Brisbane, Qld)
Liu S, Anderson JA (2003) Marker assisted evaluation of Fusarium head blight resistant wheat germplasm. Crop Science 43, 760-766.

Manly KF, Cudmore Robert H Jr, Meer JM (2001) Map Manager QTX, cross-platform software for genetic mapping. Mammalian Genome 12, 930-932. doi: 10.1007/s00335-001-1016-3

McCartney CA, Somers DJ, Fedak G, Cao W (2004) Haplotype at diversity Fusarium head blight resistance QTLs in wheat. Theoretical and Applied Genetics 109, 261-271. doi: 10.1007/ s00122-004-1640-x

Melchinger AE, Utz HF, Schon CC (1998) Quantitative trait locus (QTL) mapping using different testers and independent population samples in maize reveals low power of QTL detection and large bias in estimates of QTL effects. Genetics 149, 383-403.

Pestsova E, Ganal MW, Roder MS (2000) Isolation and mapping of microsatellite markers specific for the D genome of bread wheat. Genome 43, 689-697. doi: 10.1139/gen-43-4-689

Roder MS, Korzun V, Wendehake K, Plaschke J, Tixier MH, Leroy P, Ganal MW (1998) A microsatellite map of wheat. Genetics 149, 2007-2023.

Sharp PJ, Johnston S, Brown G, McIntosh RA, Pallotta M, Carter M, Bariana HS, Khatkar S, Lagudah ES, Singh RP, Khairallah M, Potter R, Jones MGK (2001) Validation of molecular markers for wheat breeding. Australian Journal of Agricultural Research 52, 1357-1366. doi: 10.1071/AR01052

Somers DJ, Isaac P, Edwards K (2004) A high-density microsatellite consensus map for bread wheat (Triticum aestivum L.). Theoretical and Applied Genetics 109, 1105-1114. doi: 10.1007/s00122004-1740-7

Spielmeyer W, Sharp PJ, Lagudah ES (2003) Identification and validation of markers linked to broad-spectrum stem rust resistance gene $S r 2$ in wheat (Triticum aestivum L.). Crop Science 43, 333-336.

Voorrips RE (2002) MapChart: Software for the graphical presentation of linkage maps and QTLs. Journal of Heredity 93, 77-78. doi: $10.1093 /$ jhered/93.1.77

Wallwork H, Butt M, Cheong JPE, Williams KJ (2004) Resistance to crown rot in wheat identified through an improved method for screening adult plants. Australasian Plant Pathology 33, 1-7. doi: 10.1071/AP03073

Wilcox MC, Khairallah MM, Bergvinson D, Crossa J, Deutsch JA, Edmeades GO, Gonzalez-de-Leon D, Jiang C, Jewell DC, Mihm JA, Williams WP, Hoisington D (2002) Selection for resistance to southwestern corn borer using marker-assisted and conventional backcrossing. Crop Science 42, 1516-1528.

Wildermuth GB, McNamara RB (1994) Testing wheat seedlings for resistance to crown rot caused by Fusarium graminearum Group 1. Plant Disease 78, 949-953.

Wildermuth GB, McNamara RB, Quick JS (2001) Crown depth and susceptibility to crown rot in wheat. Euphytica 122, 397-405. doi: 10.1023/A:1012947516161

Zhou W-C, Kolb FL, Bai G-H, Domier LL, Boze LK, Smith NJ (2003) Validation of a major QTL for scab resistance with SSR markers and use of marker-assisted selection in wheat. Plant Breeding 122, 40-46. doi: 10.1046/j.1439-0523.2003.00802.x

Manuscript received 28 November 2005, accepted 27 April 2006 